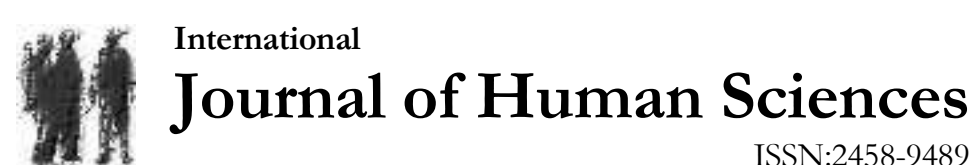

Volume 17 Issue 3 Year: 2020

\section{Comparison of pain assessments made by patients and nurses in emergency services ${ }^{1}$}

\author{
Nefise Cevriye Sucu Çakmak ${ }^{2}$ \\ Nurcan Çalışkan ${ }^{3}$
}

\begin{abstract}
Aim: This research aimed to compare pain assessments made by patients and by nurses.

Method: This descriptive and comparative research was conducted in a state, a university and a private hospital emergency service monitoring unit that had the highest number of patient admissions in Ankara, Turkey. The research sample consisted of 175 patients and 35 nurses. For the collection of data, the following sources were consulted: the patient information form, the nurse information form and the McGill Pain Questionnaire. For evaluation of the data, number and percentage calculations, chi-square analysis, kappa compliance analysis and the Wilcoxon sign test were used. Written consent was received from the ethical council and hospitals as well as from nurses and patients.

Results: $74.3 \%$ of nurses stated that they do not think that the pain level expressed by the patient is always right. While the point average given by patients related to all dimensions define the characteristics of pain was $20.48 \pm 10.10$, the average given by nurses was $14.35 \pm 8.46$. There is a statistically significant difference between the point averages given by patients and nurses related to total dimensions of pain characteristics $(\mathrm{p}<0.05)$.

Conclusion: As a result, pain evaluations of nurses were found to be significantly lower than those of patients. It is suggested that the policies and procedures used in health personnel education institutes and health institutes related to pain management should be improved.

Keywords: McGill Pain Questionnaire, pain assessment, patient, nurse, comparison, pain.
\end{abstract}

\section{Introduction}

Pain is a complicated and multidimensional phenomenon (Jahn et al., 2010). Although various pain definitions have been made, the most valid definition today is the definition of the International Organization for Pain Studies (International Association for the Study of Pain [IASP]). Pain defined by IASP as an unpleasant sensory and emotional sensation, a behavior, related to the past experiences of man, with or without strong tissue damage from a particular area of the body. (http://www.iasppain.org/Taxonomy\#Pain). In the definition made by IASP, it is seen that objective, subjective,

\footnotetext{
${ }^{1}$ Abstract of this study was presented as an oral presentation at International Conference on Nursing (ICON 2017), in First International Congress of Nursing,16 - 18 March 2017, Antalya/ Turkey.

2 RN, MSN, Çankırı Karatekin University, Eldivan Vocational School of Health Service, Turkey, nefisem-sucu@hotmail.com (iD) Orcid ID: 0000-0003-1845-9525

3 PhD, RN, Assoc. Prof., Gazi University, Faculty of Health Sciences, Nursing Department, Turkey, yildirim.nurcan@gmail.com (iD) Orcid ID: 0000-0001-9804-3030
} 
Sucu Çakmak, N. C., \& Çalışkan, N. (2020). Comparison of pain assessments made by patients and nurses in emergency services. Journal of Human Sciences, 17(3), 864-876. doi:10.14687/jhs.v17i3.5889

emotional and psychological aspects of pain are brought together. The most clinically useful definition is Mc Cafery's definition of pain. McCafery defined pain as "what the patient says, if he says it there is" (McCafery 1999). Since pain is a subjective experience, its presence and severity can only be defined by the patient. Although pain is observed in all clinics and units of a hospital, emergency services are one of the places where pain is most frequently encountered. In the literature, it is indicated that pain is a primary problem for more than $70 \%$ of patients at an emergency service and is a priority reason for admission (Butti et al., 2017; Lourens et al., 2019).

A successfulpain management begins with the assessment of pain. However, Curtiss states that there are contradictions in terms of perception of pain between patients and nurses in pain assessments (Curtiss, 2001). Examining the literature, it is observed that nurses generally underestimate the pain of patients in emergency services; do not always use a scale for assess patient's pain and keep the records of pain or share pain findings with their colleagues as well as they make use of knowledge, opinions and practices which might negatively affect pain management (Akin \&Durna, 2013; Bağdatlı\&Eşer, 2010; Davoudi,Afsharzadeh, Mohammadalizadeh, \&Haghdoost, 2008; Dequeker, Van Lancker, \& Van Hecke, 2018; Duignan \& Dunn, 2008; Modanloo et al., 2010; Ucuzal\&Doğan, 2015). This might be because of the fact that nurses prioritise physical problems in emergency services rather than healthcare services such as pain management; nurses often lack knowledge on pain management, they do not acknowledge the pain stated by patients and use their own clinical judgement instead (de Oliveira, Pereira, Santos \& Souza, 2016; Kahsay \& Pitkäjärvi, 2019; Latina, 2015.).Morever, because of positive conditions such as accepting patients without any appointment and offering rapid tests and treatments, patients' inappropriate use of emergency services might be increasing factor for contradictions in the perception of pain between patients and nurses(Bergman, 2012; Söyük\&Arslan- Kurtuluş, 2017) This contradiction may lead to insufficient treatment of pain due to unsuccessful pain management (Latina et al., 2015; Li \& Wu, 2010; Macintyre \&Schug, 2014; Miner, Paris, \&Yealy, 2010; Ortiz,Carr\&Dikareva, 2014; Van Hecke et al., 2016).

Unsuccessful pain management not only causes repeated admissions to an emergency service, where acute pain management is important, but in the long term, also leads to an extended length of hospital stay, increased cost of healthcare services, loss of labour force, an increased mortality and morbidity rate, and reduced life quality and patient satisfaction (Mackintosh \& Bowless 2009; Kahsay \& Pitkäjärvi, 2019; Latina, 2015). Therefore, it is very significant to identify the contradictions between the pain perceptions of patients and nurses (Eti-Aslan, 2005; Mackintosh \& Bowless, 2009). In a good pain assessment, it should be learned whether the patient has experienced the severity, location, quality, relationship with time, factors that increase and decrease pain, quantitative measurements, similar findings, previous treatments, general health history, pain questioning for systems, medications used by the patient and nonverbal expressions of pain should be observed (EtiAslan, 2014). In the evaluation of pain; It is necessary to make the severity and quality of the pain reported by numbers or words as objective as possible and to eliminate the different interpretations between the nurses and physicians who care for the patient and the patient. For this, the use of scales in pain assessment becomes important. One-dimensional and multi-dimensional scales are used in pain assessment. While evaluating only the severity of pain with one-dimensional scales, multidimensional scales can make multi-dimensional evaluations such as the location, feature, severity, and relationship of pain with time.

In the literature, although numerous studies on nurses' knowledge and attitudes regarding pain assessment (Bağtatlı-Aydın \& Eşer, 2010; Demir, İnce, Turken, \& Aki, 2012; Dequeker et al., 2018; Ferreira, Oliveira Guirro, Dibai-Filho, Arau’jo Ferreira, \& Almeida, 2014; Schreiber et al., 2014; Özveren et al, 2018) the number of studies comparing pain assessments of patients and nurses in emergency services is quite limited. It is seen in these studies that comparisons were made by using a unidimensional pain scale (Duignan \& Dunn, 2008; Guru \& Dubinsky, 2000; Modanloo et al., 2010; Puntillo, Neighbor, O’Neil, \& Nixon, 2003; Stalnikowicz, Mahamid, Kaspi, \&Brezis, 2005). There is no other study than this providing a comparison using a multidimensional pain scale such as McGill Pain Questionnaire, which assesses the location, depth, quality, duration and intensity of pain, in 
Sucu Çakmak, N. C., \& Çalışkan, N. (2020). Comparison of pain assessments made by patients and nurses in emergency services. Journal of Human Sciences, 17(3), 864-876. doi:10.14687/ihs.v17i3.5889

emergency services. Data obtained as a result of this study emphasize unsuccessful pain management carried out by nurses working in emergency services and the obstacles in pain management. It is thought that this study will raise awareness on pain management among nurses; promote the development of objectives and procedures for pain management in emergency services and eliminate the differences between patient's self reports and nurse's pain assessments. Therefore, this study was conducted to compare pain assessments made by patients and nurses.

\section{Methods}

\section{Design and sample}

This descriptive, comparative and sectional study was carried out with the participation of patients followed in emergency service observation units and nurses providing services to these patients in a university, state and private hospital, which have the highest number of patient admission to the emergency service in a metropolitan city of the Central Anatolia Region of Turkey.

The sample included 175 voluntary patients, who are monitored in the emergency service unit and having pain as the primary complaint; are between 18 and 65 years, communicative, speaking Turkish, able to use the pain scale and having no risk of death, and 35 nurses who accepted to participate in the study.

Nurses graduated from each level of nursing programme were included in the research. High school graduate nurses are those who received four-year high school education while those having bachelor's degree are the nurses who received four-year university education.

A statistical power analysis was performed for sample size estimation, based on data from published study (Ferreira, Oliveira Guirro, Dibai-Filho, Arau'jo Ferreira, \& Almeida, 2014). The effect size (ES) in this study was 0.30 considered to be small using Cohen's criteria. With an alpha $=.05$ and power $=.80$, the projected sample size needed with this effect size (NCSS PASS 2008 software) is approximately nursing $(\mathrm{n}=35)$ and patient $(170)$.

The number of nurses and patients accepted to the sampling are directly proportional to the number of applications to the emergency services of each hospital. Each nurse made pain assessment of five patients. 14 nurses and 70 patients from university hospital, 19 nurses and 95 patients from state hospital, and 2 nurses and 10 patients from private hospital were included in the sampling. Since it is thought unethical to make comparison between the data received from three different centres as state, university and private hospital, all these are evaluated as a single centre.

\section{Study instruments}

Patient information form, a nurse information form and the MPQ was used in the collection of data.

\section{Patient information form}

Patient information form was created in accordance with the literature (Puntillo et al, 2003; Eti 2014). This form includes seven questions about the descriptive characteristics of the patient: age, gender, marital status, education level, occupation, previous admissions to the emergency service and, if applicable, satisfaction with previous treatment.

\section{Nurse information form}

The nurse information form was created in accordance with the literature (Duignan \& Dunn, 2008; Puntillo et al, 2003). This form comprises of two parts. The first part includes eight questions about the descriptive characteristics of nurses. The second part includes 15 questions about the knowledge, opinions and practices of nurses regarding pain management. 
Sucu Çakmak, N. C., \& Çalıșkan, N. (2020). Comparison of pain assessments made by patients and nurses in emergency services. Journal of Human Sciences, 17(3), 864-876. doi:10.14687/jhs.v17i3.5889

\section{The McGill Pain Questionnaire (MPQ)}

The validity and reliability of the McGill Pain Question Form, which was developed in 1971 by Melzack and Targerson, was carried out in 2003 by Kuğuoğlu and Eti Aslan. This form consists of four sections. Information regarding name, surname, age, medical diagnosis, problem and the type and dosage of analgesics (if used) is required in the introduction section. There is information regarding patient's perception of pain and location of the pain in the first section; quality of pain in the second section; relation of pain with duration in the third section and introductory information diagnosing the level of pain in the fourth section (Kuğuoğlu, \&Eti-Aslan, 2003). Twenty-word groups, which describe the pain characteristics in the second part of the questionnaire, consist of four dimensions that show the sensory, affective, evaluative and miscellaneous aspects of pain. The scoring in this section is based on the sequence numbers of the words. In each group of word, the words are assigned points, starting from 1 for the word that least reflects the nature of the pain and 2, 3 for the others respectively. The total score is obtained by adding all group scores (Kuğuoğlu \& Eti-Aslan, 2003; Melzack, 2005). The Cronbach's alpha for the MPQ is 0.98 (Kuğuoğlu \& Eti-Aslan, 2003). The Cronbach's alpha obtained in this study is 0.70 .

\section{Data collection}

The study was conducted between December 25, 2014, and February 15, 2015 with the participation of patients being monitored and nurses working in emergency service observation units at a university, state and private hospital.

The researcher obtained written approval from the voluntary patients and nurses in the observation unit. The patient and nurse information forms were filled by the researcher with the technique of face-to-face interviews. Each nurse evaluated the pain of a patient under the supervision of the researcher and then left the patient. The nurses filled their patients' pain assessments by using MPQ at the nursing desk after leaving the patient. Each patient, on the other hand, performed a selfpain evaluation by using the MPQ immediately after the nurse left. The researcher read patient information form aloud for patients who were unable to fill out the forms. The researcher accompanied the patients during pain assessments, which were conducted by nurses and patients concurrently.

\section{Data analysis}

The statistical analyses were performed using the Statistical Package for the Social Sciences (SPSS, version 14). Number and percentage calculations, chi-square analysis, Cohen's kappa analysis and the Wilcoxon signed-rank test were used in the evaluation of data. The data were evaluated at a $\mathrm{p}<0.05$ significance level and a $95 \%$ confidence interval.

\section{Ethical approvals}

For this study, the approval of the ethical committee of Gazi University (dated 25.06.2014 and numbered 77082166-604.01.02-17783) and written permission from the participating hospitals were obtained. The patients and nurses were informed about the purpose of the study and the study plan, and their informed consents were obtained. 
Sucu Çakmak, N. C., \& Çalışkan, N. (2020). Comparison of pain assessments made by patients and nurses in emergency services. Journal of Human Sciences, 17(3), 864-876. doi:10.14687/ihs.v17i3.5889

\section{Results}

Table 1 Personal information about the patients $(n=175)$

n $\%$

Personal information about the patients

Mean \pm SD

\begin{tabular}{|c|c|c|}
\hline \multicolumn{3}{|l|}{ Age (years) } \\
\hline Minimum-maximum & \multirow{2}{*}{\multicolumn{2}{|c|}{$\begin{array}{c}18-65 \\
38,79 \pm 13,58\end{array}$}} \\
\hline Mean \pm SD & & \\
\hline \multicolumn{3}{|l|}{ Gender } \\
\hline Women & 101 & 57,7 \\
\hline Men & 74 & 42,3 \\
\hline \multicolumn{3}{|l|}{ Marital status } \\
\hline Married & 114 & 65,1 \\
\hline Single & 61 & 34,9 \\
\hline \multicolumn{3}{|l|}{ Educational background } \\
\hline Illiterate & 9 & 5,1 \\
\hline Primary school & 40 & 22,9 \\
\hline High school & 25 & 14,3 \\
\hline Under- and postgraduate degrees & 101 & 57,7 \\
\hline \multicolumn{3}{|l|}{ Employment status } \\
\hline Working & 87 & 49,7 \\
\hline Not working & 88 & 52,3 \\
\hline \multicolumn{3}{|c|}{ Whether presented with pain to an emergency } \\
\hline Yes & 55 & 31,4 \\
\hline No & & \\
\hline
\end{tabular}

Table 1 shows that 175 patients participated in the study. Of the patients involved in the study, $57.7 \%$ were women, and average age of patients was $38.7 \pm 13.5$ years. According to the results, $68.6 \%$ of the patients were previously admitted to the emergency department with complaints of pain; $74.2 \%$ thought their pain had been treated satisfactorily during their previous admission.

Table 2 Personal information about the nurses and their knowledge, views and practices related to pain management $(n=35)$

Personal information about the nurses and their knowledge, views and practices related to pain management

Mean \pm SD

\begin{tabular}{|c|c|c|}
\hline \multirow{2}{*}{\multicolumn{3}{|c|}{ Age (years) }} \\
\hline & & \\
\hline Minimum-maximum & \multicolumn{2}{|c|}{$21-44$} \\
\hline Mean \pm SD & \multicolumn{2}{|c|}{$29,17 \pm 5,66$} \\
\hline \multicolumn{3}{|c|}{ Years of Service in Emergency Department } \\
\hline Minimum-maximum & \multicolumn{2}{|c|}{$1-10$} \\
\hline Mean \pm SD & \multicolumn{2}{|c|}{$3,23 \pm 2,34$} \\
\hline \multicolumn{3}{|l|}{ Gender } \\
\hline Women & 29 & 82,9 \\
\hline Men & 6 & 17,01 \\
\hline \multicolumn{3}{|l|}{ Educational background } \\
\hline High school & 9 & 25,7 \\
\hline Under- and Postgraduate degrees & 26 & 74,3 \\
\hline \multicolumn{3}{|l|}{ Working mode } \\
\hline Permanently at night work & 5 & 14,3 \\
\hline Permanently at day work & 12 & 34,3 \\
\hline On-call service / shift work & 18 & 51,4 \\
\hline
\end{tabular}


Sucu Çakmak, N. C., \& Çalışkan, N. (2020). Comparison of pain assessments made by patients and nurses in emergency services. Journal of Human Sciences, 17(3), 864-876. doi:10.14687/ihs.v17i3.5889

\begin{tabular}{|c|c|c|}
\hline \multicolumn{3}{|l|}{ Whether or not nurses are responsible for pain management } \\
\hline Are responsible & 22 & 62,9 \\
\hline Are not responsible & 13 & 37,1 \\
\hline \multirow{2}{*}{\multicolumn{3}{|c|}{$\begin{array}{l}\text { Whether the patient could correctly express her/himself in respect of pain } \\
\text { sensation }\end{array}$}} \\
\hline & & 25,7 \\
\hline Yes & 26 & 74,3 \\
\hline \multicolumn{3}{|l|}{ No } \\
\hline Whether utilization of a scale is important for pain assessment & 5 & 14,3 \\
\hline Partly important & 11 & 31,4 \\
\hline Of medium importance & 19 & 54,3 \\
\hline \multicolumn{3}{|l|}{ Very important } \\
\hline Use of pain assessment scale & 3 & 8,6 \\
\hline Users & 32 & 91,4 \\
\hline \multicolumn{3}{|l|}{ Non-users } \\
\hline Whether the frequency of pain assessment and recording is important & 1 & 2,9 \\
\hline Not important & 6 & 17,1 \\
\hline Partly important & 11 & 31,4 \\
\hline Of medium importance & 17 & 48,6 \\
\hline \multicolumn{3}{|l|}{ Very important } \\
\hline Status of recording pain assessment findings & 5 & 8,6 \\
\hline Registered & 30 & 91,4 \\
\hline \multicolumn{3}{|l|}{ Unregistered } \\
\hline Nurses facing barriers in pain management in emergency departments & 27 & 77,1 \\
\hline Have faced & 8 & 22,9 \\
\hline \multicolumn{3}{|l|}{ Have not faced } \\
\hline Pain management barriers by nurses in the emergency department * & 22 & 81,5 \\
\hline Workload excess & 10 & 37,0 \\
\hline Lack of standard practices related to the management of pain relief & 10 & 37,0 \\
\hline Lack of usage of a standard pain rating & 10 & 37,0 \\
\hline Insufficiency of pain assessment records & 9 & 33,3 \\
\hline Insufficient cooperation by physicians & 8 & 29,6 \\
\hline Awareness of the side effects of the drugs used in pain management & 7 & 25,9 \\
\hline Insufficient cooperation by patients on medication & 5 & 18,5 \\
\hline Emergency care is not a priority for pain management & 5 & 18,5 \\
\hline Inadequate equipment for pain management & 3 & 11,1 \\
\hline Lack of information on pain management & 3 & 11,1 \\
\hline Inadequate dosing of analgesic drugs & & \\
\hline
\end{tabular}

$*$ ' $n$ ' is folded because more than one option is marked. The percentages are taken over ' $n$ '.

Table 2 shows that 35 nurses participated in the study. Of the nurses who participated in the study, $62.9 \%$ stated that pain management was under the responsibility of the nurse, and $74.3 \%$ did not always find the level of pain expressed by patients to be accurate.

Moreover, $91.4 \%$ of the nurses stated they did not use a standard pain evaluation scale in their services, and $85.7 \%$ did not record evaluation findings. The rate of situations in which nurses encountered a barrier/problem in relieving the pain of patients in emergency services is \% 77.1. $81,5 \%$ of nurses considers heavy workload as a barrier//problem in relieving the pain of patient in an emergency service. 
Sucu Çakmak, N. C., \& Çalışkan, N. (2020). Comparison of pain assessments made by patients and nurses in emergency services. Journal of Human Sciences, 17(3), 864-876. doi:10.14687/ihs.v17i3.5889

Table 3 Breakdown of the answers given by patients and nurses in words expressing the severity and location of the pain $(n=175)$

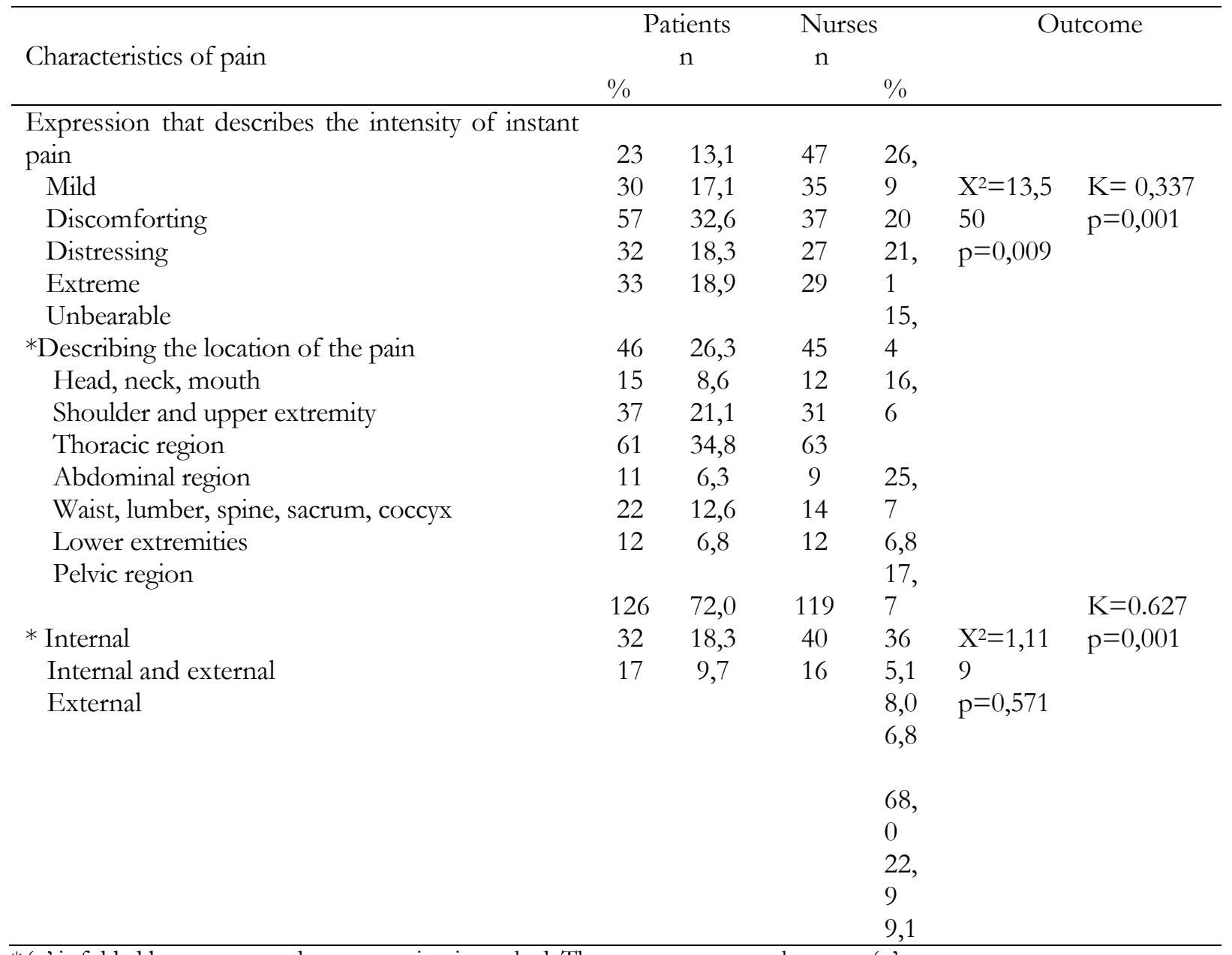

* ' $n$ ' is folded because more than one option is marked. The percentages are taken over ' $n$ '.

Examining the distribution of answers given by patients and nurses related to the words which describe current pain severity, it is found out that 32.6\% $(n=57)$ of the patients chose the word 'distressing', while $26.9 \%(\mathrm{n}=47)$ of the nurses preferred the word 'mild'. There was a statistically significant difference between the answers of the patients and nurses about words which describe the current pain severity $(\mathrm{p}<0.05)$. However, there was a statistical comformity between the answers of the patients and nurses $(\mathrm{p}<0.05)$ and it was weak $(K=0.337)$.

There was no statistically significant difference between the answers of the patients and nurses about the words which describe the location of pain $(p<0.05)$. There was a sufficient level of statistical comformity between the patients' and nurses' answers $(\mathrm{p}<0.05 ; \mathrm{K}=0.627)$.

Table 4 Breakdown of the answers given by patients and nurses about the dimensions that define the characteristics of the pain $(n=175)$

\begin{tabular}{llcl}
\hline $\begin{array}{l}\text { Dimensions that describe the characteristics of the } \\
\text { pain }\end{array}$ & $\begin{array}{l}\text { Patients } \\
\mathrm{x} \pm \mathrm{Ss}\end{array}$ & $\begin{array}{c}\text { Nurses } \\
\mathrm{x} \pm \mathrm{Ss}\end{array}$ & $\begin{array}{l}\text { Outcom } \\
\mathrm{e}\end{array}$ \\
\hline Sensory & & & $\begin{array}{l}\mathrm{Z}=- \\
6,468\end{array}$ \\
Affective & $10,95 \pm 6,19$ & $7,89 \pm 5,21$ & $\begin{array}{l}\mathrm{P}=0,001 \\
\end{array}$ \\
& $3,16 \pm 2,65$ & $2,7 \pm 2,34$ & $\begin{array}{l}\mathrm{Z}=- \\
5,077 \\
\mathrm{P}=0,001\end{array}$ \\
\hline
\end{tabular}


Sucu Çakmak, N. C., \& Çalıșkan, N. (2020). Comparison of pain assessments made by patients and nurses in emergency services. Journal of Human Sciences, 17(3), 864-876. doi:10.14687/jhs.v17i3.5889

\begin{tabular}{lccl} 
Evaluative & $2,05 \pm 1,82$ & $1,44 \pm 1,72$ & $Z=-$ \\
& & & 3,874 \\
& & & $P=0,001$ \\
Miscellaneous & $4,33 \pm 3,22$ & $2,95 \pm 2,84$ & $Z=-$ \\
& & & 5,398 \\
& & & $P=0,001$ \\
Total & & & $Z$ \\
& $20,48 \quad \pm$ & $14,35 \pm 8,46$ & 7,929 \\
& 10,10 & & $P=0,001$ \\
\hline
\end{tabular}

$*$ The Wilcoxon sign test was used for this calculation.

There was a statistically significant difference between the average scores given by patients and nurses for all dimensions of pain $(p<0.05)$. The average scores of the nurses in all dimensions of pain were significantly lower than those of the patients.

Although it was not provided in the tables, the relationship of the nurses' pain assessments with their level of education was examined, and the following findings were obtained. There was a statistically significant difference between the nurses' education level and the words which describe the current pain severity $(\mathrm{p}<0.05)$. Nurses with bachelor's degree or postgraduate degree assigned significantly higher scores to all dimensions that define pain characteristics than nurses with a high school education did. Nurses with high school education scored level of pain less than those with bachelor's degree or postgraduate degree.

\section{Discussion}

Although the most reliable source for pain assessment is the statement of the individual in pain, there are evidences that healthcare professionals do not ask questions to patients regarding the pain; they frequently use their own clinical judgements in pain reporting and ignore the pain of patients who they do not observe a clear physical abnormality (Akın \&Durna, 2013; Bağdatlı\&Eşer, 2010; Duignan \& Dunn, 2008; Modanloo et al., 2010; Yildırım\&Uyar, 2006). In the literature, since there are limited studies that comparing pain assessments using the multidimensional pain scale of patients and nurses in emergency services, the discussion was made on the based of this limited literature.

In this study, the average scores of the nurses for all dimensions defining pain characteristics were significantly lower than those of the patients (Table 4). Similarly, in the study where Düzel (2008) compared the pain assessments of nurses and postoperative patients using the MPQ, it was found out that there wasa significant difference between the scores of patients and nurses in all dimensions showing pain-characteristic. The reason of low average scores could be that the nurses recorded their own opinions regarding the pain of patient rather than the self-pain reports of patients although they expressed that they assessed the characteristics of pain. Another explanation is related to patients' use of emergency services. In Turkey, is a well-known fact that patients who cannot get an appointment for a polyclinic, apply to the emergency department for quick access to health services (Söyük\&ArslanKurtuluş, 2017). Patients' s improper use of emergency service can lead nurses to think that patients exaggerate the pain. Nurses in emergency services must evaluate the pain of patients within a limited time frame, which may also cause contradictions on pain perceived by nurses and patients. Discrepancies between patients' self-pain reports and nurses' pain assessments affects the management of pain negatively.

Although there is a statistically significant difference between the answers of the patients and nurses with regard to the words that describe the current pain level (Table 3), there was a statistically weak comformity $(K=0.337)$. A similar result was obtained for this comparison in Düzel's study (2008), although it had a different patient group than the present study. Statistical comformity, though weak, was obtained between the patient and nurse scores (gamma correlation coefficient $=0.346$ ); the weak level of comformity indicates unsuccessful pain management. Level of pain can vary among 
Sucu Çakmak, N. C., \& Çalışkan, N. (2020). Comparison of pain assessments made by patients and nurses in emergency services. Journal of Human Sciences, 17(3), 864-876. doi:10.14687/jhs.v17i3.5889

individuals with acute pain depending on age, gender, personality and culture. Patients can develop anxiety and agitation as a result of acute pain and waiting for a long time for the relief of pain in emergency services. Furthermore, deterioration in perception of pain can be seen depending on the patient's previous experiences. Therefore difference in the perception of patient' and nurses' level of pain may increase .In the literature, the research findings from different participant samples are parallel to the current study in that nurses determine the patient's pain severity to be lower than the level expressed by patients (Akın \&Durna, 2013; BağdatlıEşser, 2010; Davoudi et al., 2008; Duignan \&Dunn, 2008; Guru \& Dubinsky, 2000; Idvall, Berg, Unosson, \&Brudin, 2005; McCaffery, Ferrell, \&Pasero, 2000; Modanloo et al., 2010; Puntillo et al., 2003; Sloman, Rosen, Rom, \&Shir, 2005; Stephenson, 1994).

In this study, no statistically significant difference was found between the answers of the patients and nurses for the words defining the location of pain and sufficient statistical comformity was obtained between the answers of the patients and nurses (Table 3). Although different group of patients attended the study, Düzel $(2008)$ reported similar findings $(p<0.001)$ and statistical comformity was obtained for the scores given by patients and nurses (Gamma correlation coefficient of 0.732 ). Although it can be concluded that patients and nurses are in harmony regarding the location of pain, good pain assessment has further dimensions.

Due to the roles of nurses in spending more time with patients compared to other healthcare personnel and relieving pain, it is important for nurses to have knowledge on pain management and transform this knowledge into attitude and practices (Eti-Aslan, 2014; Yücel, 2007). The prerequisite for understanding the patient's pain is that nurses should have sufficient knowledge and willing. Meticulously collecting data regarding complicated and multidimensional nature of pain will enable nurses better understand the pain of patients. In the study, although more than half of nurses knew that pain management was under their responsibility, they stated that pain expressed by the patient was not always found true by themselves. As it is understood from the quotation 'pain is what the patient says, and if the patient says he or she has pain, there is pain' by Mc Caffery and Beebe (1989, p.7) believing the patient in pain is very important in evaluating and controlling their pain.

In the literature, importantly, the nurses did not always use a standardised scale for pain assessment (Demir, İnce, Turken, \& Aki, 2012; Özveren et al., 2018). Using standardised scales in pain assessment converts the statement of pain into numerical values, creates a common language for the pain perception of patient and healthcare personnel and, thus, improves the efficiency of pain management (Eti-Aslan, 2005; Pasero, Mc Caffery 2000) It is concerning that although more than half of the nurses in the study believed using a scale in pain assessment was important, the rate of nurses using such a scale was very low. While almost half of the nurses found pain assessment and recording frequency important, most stated they did not record findings of pain assessment (Table 2). If the nurses do not record the findings of pain assessments, they will not have an opportunity to monitor and evaluate the pain of patients. Also, they cannot prove the works they did even they make pain assessment. Similar results have been also reached in literature (Abdalrahim,Majali\&Bergbom, 2008; Demir, İnce, Turken, \& Aki, 2012; Ucuzal\&Doğan, 2015).

The literature shows that nurses, like other healthcare professionals, do not have sufficient knowledge, experience, practice about pain, and this lack of knowledge negatively affects pain management (Aslan \&Badır, 2005; Ay \& Ecevit, 2010; Demir, İnce, Turken, \& Aki, 2012; Dequeker et al., 2018; Duignan \& Dunn, 2008; Puntillo et al., 2003; Sloman et al., 2005; Ucuzal\&Doğan, 2015; Yildırım, 2013). Lack of knowledge about pain may be related to education. In this study, a significant difference was obtained between the education levels of nurses and their mean scores in all aspects defining the nature of the pain, as nurses with a bachelor's degree or higher assigned significantly higher scores than did nurses with a high school education. Studies by Bağtatll-Aydın and Eşer (2010), Schreiber et al. (2014) and Zalon (1993), using different measurement tools and samples, have demonstrated that education makes a difference in pain management, parallel to the findings of the current study. However, Düzel (2008) and Sloman et al. (2005) concluded that education did not make a difference in pain management. In literature, since there are studies showing both positive 
Sucu Çakmak, N. C., \& Çalışkan, N. (2020). Comparison of pain assessments made by patients and nurses in emergency services. Journal of Human Sciences, 17(3), 864-876. doi:10.14687/jhs.v17i3.5889

(Zalon, 1993) and neutral effects of education level (Düzel, 2008; Slamon et al, 2005) on pain management, studies, having high evidential value and revealing the effect of education level on pain management, are required.

Regarding the high rate of experiencing problems with patients' pain managament in emergency services assigned by the nurses, there are several explanations. As mentioned, most of the nurses identified high workload as a barrier, while more than one-third of the nurse participants mentioned lack of standardised practices for pain management as an barriers. The absence of a standard pain assessment scale and insufficient records of pain assessment are additional barriers to pain relief for patients in emergency services (Table 2). These findings are believed to be related to a lack of nurse education and knowledge, positively affecting the attitudes and practices of nurses. The number of emergency service application is high in the hospitals where this study has been carried out. Although triage application is conducted in emergency services, admission of those who do not need immediate treatment is also made. Since the number of patients is high in emergency services, nurses only administer medication in a quick way and do not care the issues regarding pain management. Because of all these reasons, lack of organisational objectives, protocols and training of nurses on pain management in emergency services affected the findings of our study. Overall, the findings of this study are similar to those of Bergman (2012), Pretorius, Searle and Marshall (2015), Ucuzal and Doğan (2015), de Oliveira, Pereira, Santos \& Souza, (2016).

This study revealed the failure of nurses in pain management in emergency departments and the factors that cause it. Contrary to the studies in the literature, multi dimensional pain scale has been used to compare pain assessment of patients and nurses in emergency services in our study (Guru, \& Dubinsky, 2000; Puntillo, Neighbor, O’Neil, Nixon, 2003; Duignan \& Dunn, 2008; Modanloo, SeyyedFatemi, Bastani, Peyravy, Behnampoor, Hesam\&Abdollahi, 2010). With the multidimensional scale, it has been identified which scales of pain assessment are not taken care by nurses in emergency services. Although nurses adjusted themselves in examining location of pain, they underestimated the pains of patients in terms of the quality and level of pain. This is an important finding in terms of literature.

\section{Limitations of the study}

The main limitation of this research was that it was performed in hospitals located in only one of the provinces in Turkey.

\section{Conclusion}

In this study, the pain assessments of nurses and patients in emergency services were compared using the MPQ. It was found that nurses 'pain assessments were significantly lower than patients' self-assessments. The conformity between the patient's self-assessments and the nurses' assessments of patient pain increased with higher education levels among nurses. In this study, although the majority of the nurses are aware of the pain management is the responsibility of the nurse, it was found that although they do not always find the pain expressed by the patient correctly, they do not use a standard scale when evaluating the pain and do not record the pain assessment findings, they encounter obstacles in pain management and the workload is at the top of these obstacles.

Based on the findings of the study, it is recommended that awareness of acute pain management should be raised among nurses working in emergency services by offering opportunities for nursing training in accordance with their requirements; dtraining should be delivered with the techniques of simulation, creative drama and case discussion to allow nurses to reflect acquired knowledge in behaviour by changing classical methods regarding pain management delivered during their basic vocational education; objectives and protocols on acute pain management should be developed and implementation of the protocols should be supervised in health institutions; inappropriate admission of patients should be prevented through triage implementation and the number of patients should be decreased.., It is recommended to repeat this study to identify the differences between nurses that use standardised pain scales and those that do not. 
Sucu Çakmak, N. C., \& Çalışkan, N. (2020). Comparison of pain assessments made by patients and nurses in emergency services. Journal of Human Sciences, 17(3), 864-876. doi:10.14687/ihs.v17i3.5889

\section{Acknowledgements}

The authors would like to thank all individuals who participated in this study.

\section{Conflicts of interest}

The authors declare that they have no conflicts of interest.

\section{Author contributions}

N.C.S.Ç and N.Ç. decided on the research design, and N.C.S.Ç. acquired the data and carried out the data coding, analysis and manuscript composition. N.C.. supervised the whole study process and critically reviewed the manuscript. Both authors read and approved the final manuscript.

\section{REFERENCES}

Abdalrahim, M. S., Majali, S. A., \& Bergbom, I. (2008). Documentation of postoperative pain by nurses in surgical wards. Acute pain, 10(2), 73-81.

Akın, S., \& Durna, Z. (2013). A comparative descriptive study examining the perceptions of cancer patients, family caregivers, and nurses on patient symptom severity in Turkey. European Journal of Oncology Nursing, 17(1), 30-37.

Ay, F., \& Ecevit, A.Ş. (2010). Post operatif ağr1 ve hemşirelik uygulamaları. [Postoperative pain and nursing practices]. Pain,22(1), 21-29.

Bağtatli-Aydın, H. \& Eşer İ. (2010). Hemşirelerin ve kanserli hastaların ağrı değerlendirmelerinin karşılaştırılması [Comparison of pain evaluations of nurses and cancer patients]. Ege University Journal of Nursing High School, 26(1), 11-23.

Bergman, C. L. (2012). Emergency nurses' perceived barriers to demonstrating caring when managing adult patients' pain. Journal of Emergency Nursing, 38(3), 218-225.

Butti, L., Bierti, O., Lanfrit, R., Bertolini, R., Chittaro, S., Compagni, S. D., ... \& Pertoldi, F. (2017). Evaluation of the effectiveness and efficiency of the triage emergency department nursing protocol for the management of pain. Journal of pain research, 10, 2479.

Curtiss, C.P. (2001). Meeting the standards for pain management. Orthopedic Nursing,20(2), 27-35.

Davoudi, N., Afsharzadeh, P., Mohammadalizadeh, S., \& Haghdoost, A. (2008). A comparison of patients' and nurses' assessments of pain intensity in patients with coronary artery disease. International Journal of Practice, 14(5), 347-356.

Demir, Y., İnce, Y., Turken, K., \& Aki, M. (2012). Hemşirelerin ağrı yönetimi ile ilgili bilgi, davranış ve klinik karar verme durumlarının belirlenmesi [Determination of information, behaviour and clinical decision making of nurses about pain management]. Journal of Contemporary Medicine, 2(3), 162-172.

Dequeker, S., Van Lancker, A., \& Van Hecke, A. (2018). Hospitalized patients' vs. nurses' assessments of pain intensity and barriers to pain management. Journal of Advanced Nursing,74, $160-171$

Duignan, M., \& Dunn, V. (2008). Congruence of pain assessment between nurses and emergency department patients: A replication. International Emergency Nursing, 16, 23-28.

Düzel, V. (2008). Hemşirevehastalarmpostoperatifağrndeğerlendirmelerininkarşılașılaștırlması [Comparison of postoperative pain evaluations of nurses and patients]. (Master's thesis). Cukurova University, Nursing Department, Adana.

Eti-Aslan F. (2005). Akutağr1 [Acute pain]. Journal of Nursing Education and Research,2 (1), 24-31.

Eti-Aslan, F. (2014). Ağr Doğası ve Kontrolï [Pain nature and control]. Akademisyen Medical Book House, 2nd Edition, Ankara.

Ferreira V. T., Oliveira Guirro, E. C., Dibai-Filho, A. V., Arau’jo Ferreira, S.M., \& Almeida, A.M. (2014). Characterization of chronic pain in breast cancer survivors using the McGill Pain Questionnaire. Journal of Bodywork \& Movement Therapies, 1-5. 
Sucu Çakmak, N. C., \& Çalışkan, N. (2020). Comparison of pain assessments made by patients and nurses in emergency services. Journal of Human Sciences, 17(3), 864-876. doi:10.14687/jhs.v17i3.5889

Guru, V., \& Dubinsky, I. (2000). The patient vs. caregiver perception of acute pain in the emergency department. Journal of Emergency Medicine, 18(1), 7-12.

Idvall, E., Berg, K., Unosson, M., \& Brudin, L. (2005). Differences between nurse and patient assessments on postoperative pain management in two hospitals. Journal of Evaluation in Clinical Practice, 11(5), 444-451.

Jahn, P., Kitzmantel, M., Renz, P., Kukk, E., Kuss, O., Thoke-Colberg, A. . . .Landenberger, M. (2010). Improvement of pain related self-management for oncologic patients through a transinstitutional modular nursing intervention: Protocol of a cluster randomized multicenter trial. Trials, 11, 29.

Kahsay, D. T., \& Pitkäjärvi, M. (2019). Emergency nurses' knowledge, attitude and perceived barriers regarding pain Management in Resource-Limited Settings: cross-sectional study. BMC nursing, 18(1), 56.

Kuguluoglu, S.\& Eti-Aslan, F. (2003). McGill Melzack Ağr1 Soru Formu'nun Türkçe'ye uyarlanması [Adaptation of McGill Pain Questionnaire to Turkish]. Pain Journal,15, 47-51.

Latina, R., Mauro, L., Mitello, L., D’Angelo, D., Caputo, L., De Marinis, M. G. . . Baglio, G. (2015). Attitude and knowledge of pain management among Italian nurses in hospital settings. Pain Management Nursing, 16(6), 959-967.

Li, S. Z., \& Wu, S. L. (2010). Postoperative pain: Comparative differences between that reported by patients and nurses. [The Journal of Nursing], 57(3), 60-68.

Lourens, A., McCaul, M., Parker, R., \& Hodkinson, P. (2019). Acute pain in the African prehospital setting: a scoping review. Pain Research and Management, 2019.

Macintyre, P. \& Schug, S. (2015). Acute pain management: A practical guide. (4th ed.). CRC Press, Florida, $7-49$.

Mackintosh, C. \& Bowless, S. (2009). The effect of an acute pain service on nurses' knowledge and beliefs about post operativepain. Journal of Clinical Nursing, 9(1), 119-126.

Melzack, R. (2005). The McGill Pain Questionnaire from description to measurement. anesthesiology. The Journal of the American Society of Anesthesiologists, 103(1), 199-202.

Mc Caffery, M. and Pasero C. (1999). Pain: clinical manual, ed 2, St. Louis, Mosby.

McCaffery, M., \& Beebe, A. (1989). Pain: Clinical manual for nursing practice. St. Louis, MO: C. V. Mosby.

McCaffery, M., Ferrell, B. R., \& Pasero, C. (2000). Nurses' personal opinions about patients' pain and their effect on recorded assessments and titration of opioid doses. Pain Management Nursing, 1(3), 79-87.

Miner, J.R., Paris, P. M., \& Yealy, D. M. (2010). Pain management. In J. A. Marx, R.S. Hockberger, R.M. Walls, J.G. Adams, W.G. Barsan, M. H. Biros. (Eds.). Rosen's emergency medicine concepts and clinical practice (7th ed.; pp. 2410-2428). Saunders, An Imprint of Elsevier Inc.

Modanloo, M., Seyyed Fatemi, N., Bastani, F., Peyravy, H., Behnampoor, N., Hesam, M. \&Abdollahi, H. (2010). Comparison of pain assessment by patients and triage nurses. Iranian Journal of Critical Care Nursing Spring, 3(1), 23-28.

de Oliveira, P. E. P., Pereira, L. V., Santos, N. R., \& Souza, L. A. F. (2016). Nursing in pain management at urgency and emergency care units. Revista Eletrônica de Enfermagem, Vol 18, Iss 0 .

Ortiz, M. M., Carr, E., \&Dikareva, A. (2014). An integrative review of the literature on pain management barriers: Implications for the Canadian clinical context. Canadian Journal of Nursing Research, 46(3), 65-93.

Özveren, H., Faydalı, S., Gülnar, E., \& Dokuz, H. F. (2018). Hemşirelerin ağrı değerlendirmesine ilisskin tutum ve uygulamalar1. Journal of Contemporary Medicine, 8(1), 60-6.

Pasero, C. and Mc Caffery, M. (2000). When patient can't report pain. American Journal of Nursing. 100(9): 22-23.

Pretorius, A., Searle, J., \& Marshall, B. (2015). Barriers and enablers to emergency department nurses' management of patients' pain. Pain Management Nursing, 16(3), 372-379. 
Sucu Çakmak, N. C., \& Çalışkan, N. (2020). Comparison of pain assessments made by patients and nurses in emergency services. Journal of Human Sciences, 17(3), 864-876. doi:10.14687/jhs.v17i3.5889

Puntillo, K., Neighbor, M., O’Neil, N. \& Nixon, R. (2003). Accuracy of emergency nurses in assessment of patients' pain. Pain Management Nursing, 4(4), 171-175.

Schreiber, J. A., Cantrell, D., Moe, K. A., Hench, J., McKinney, E., Lewis, C. P. ... Brockopp, D. (2014). Improving knowledge, assessment, and attitudes related to pain management: Evaluation of an intervention. Pain Management Nursing, 15(2), 474-481.

Sloman, R., Rosen, G., Rom, M., \& Shir, Y. (2005). Nurses assessment of pain in surgical patients. Journal of Advanced Nursing, 52(2), 125-132.

Söyük, S., \& Arslan- Kurtuluş, S. (2017). Acil Servislerde Yaşanan Sorunların Çalışanlar Gözünden Değerlendirilmesi. [The evaluation of the problems in the emergency services from employee perspectives]. Gümüshane University Journal of Health Sciences, 6(4), 44-56.

Stalnikowicz, R., Mahamid, R., Kaspi, S., \&Brezis, M. (2005). Undertreatment of acute pain in the emergency department: A challenge. International Journal for Quality in Health Care, 17(2), 173 176.

Stephenson, N. L. (1994). A comparison of nurse and patient: Perceptions of postsurgical pain. Journal of Intravenous Nursing: The Official Publication of the Intravenous Nurses Society, 17(5), 235-239.

Ucuzal, M., \& Doğan, R. (2015). [Emergency nurses' knowledge, attitude and clinical decision making skills about pain]. International Emergency Nursing, 23(2), 75-80.

Van Hecke A., Van Lancker A., De Clercq B., De Meyere C., Dequeker S, Devulder J. (2016). Pain intensity in hospitalized adults: A multilevel analysis of barriers and facilitators of pain management. Nursing Research, 65, 290-300.

Yildırım, A. (2013). Total Dįproteri Ameliyati Olan Hastalarda Postoperatif Agrinin Tanilanmasi ve Agri Yonetimi [Diagnosis of postoperative aggression and management of pain in patients with total knee prosthesis]. Istanbul: Istanbul University Nursing Principles Program.

Yıldırım, Y.K., \&Uyar, M. (2006). Etkili kanser ağrı yönetimindeki bariyerler [Barriers to effective cancer pain management]. Pain, 18, 12-9.

Yücel, A. (2007). Ağr kontrolünde hemsirirenin rolü [Role of the nurse in pain control]. In S. Erdine (Ed.), Pain(pp. 695-698). Istanbul:Alemdar Printing.

Zalon, M. C. (1993). Nurses assessment of post-operative patients' pains. Pain,54, 329-334. 